\title{
PREVALÊNCIA DE ANSIEDADE EM ESTUDANTES UNIVERSITÁRIOS
}

Michelle Cardoso Machado dos Santos, Mateus Dias Antunes, Regiane da Silva Macuch, Fabiana Nonino de Sá e Patricia Cesar Nascimento Peres

UNICESUMAR
michelle.machado@unicesumar.edu.br

Acesso DOI: http://dx.doi.org/10.34059/ciejop.2019v28i1-12

Introdução: os desafios acadêmicos do ambiente universitário exigem diversas mudanças e adaptações na rotina e nos hábitos de vida dos alunos, o que pode predispor à ansiedade, estresse e até depressão. Dentre diversas condições que interferem a saúde, a ansiedade é um sintoma de maior prevalência neste grupo. Já está evidenciado que este momento ao ingressar o ensino superior, esta transição gera ansiedade dependendo da estrutura do ciclo básico, da formulação da grade curricular, dos horários disponibilizados para os alunos e do número de demandas, além disso, das características individuais de cada aluno. Objetivo: identificar a prevalência de ansiedade em estudantes de um Centro Universitário no Noroeste do Paraná. Metodologia: estudo transversal, quantitativo, no qual foi incluída uma amostra por conveniência, incluindo 181 acadêmicos de ambos os sexos, compreendendo todas as faixas etárias, matriculadas regularmente em uma instituição de ensino superior localizada no noroeste do Paraná. Este estudo foi aprovado pelo Comitê de Ética e Pesquisa do Centro Universitário de Maringá UNICESUMAR sob o parecer número 1.627.138. Foi utilizado um questionário semiestruturado pelos pesquisadores com os dados pessoais (idade, sexo e estado civil) e presença de ansiedade ( $\mathrm{sim} / \mathrm{não}$ ). Os dados foram tabulados e tratados no software Microsoft Excel versão 2010 por meio da estatística descritiva. Resultados: a média de idade foi de $20,9 \pm 3,9$ anos e a maioria $(82 \%)$ era do sexo feminino, solteiro (92\%) e a prevalência de ansiedade foi de $81 \%$ na população estudada. Conclusão: a ansiedade teve alta prevalência nos estudantes pesquisados. Nesse sentido, se faz importante identificar a prevalência de ansiedade de estudantes universitários a fim de planejar intervenções para melhorar a relação ansiedade e ensino-aprendizagem, bem como, desenvolver e implantar ações de promoção da saúde específicas para estes grupos.

Palavras-chave: Estudantes Universitários; Transtornos de Ansiedade; Promoção da Saúde. 